\title{
The Semiotic Analysis on the Appearance of Chinese and American Pavilions in Shanghai Expo
}

\author{
Shirong Zhang \\ Lanzhou University of Technology, Lanzhou, China \\ Email: yfan6013@163.com \\ Fan Yang \\ Lanzhou University of Technology, Lanzhou, China \\ Email: yfan6013@163.com
}

\begin{abstract}
To avoid the inconvenience caused by cultural misunderstanding, it is necessary to get to know other cultures. World expo provides a chance for people to learn different cultures. As the representatives of their countries, appearance of pavilions can reflect their unique culture vividly. From the perspective of semiotics, this paper mainly analyzes the cultural connotations reflected in the elements of Chinese and American pavilions' appearance. The paper also discusses the deep roots of differences of the two cultures with the help of Kluckhohn and Strodtbeck's value orientations.
\end{abstract}

Index Terms - semiotics, appearance, cultural connotations, Chinese and American pavilions, Shanghai expo

\section{INTRODUCTION}

As the rapid development of science and technology, the communication between different cultures becomes more necessary and possible. Therefore, it is of great importance to learn how to communicate effectively and obtain profound knowledge of different cultures. World expo is a grand meeting which combines world economy, science and technology and culture from different areas. It not only shows new conceptions and techniques, but also reflects features of various cultures. Under the theme of "Better City, Better Life", each pavilion in Shanghai expo has contributed to display its distinguishing cultural features.

The former studies on Shanghai expo2010 pay more attention to the distinct signs, such as the emblem, slogans and mascot in order to introduce the theme reflected by the signs. However, the significance of pavilion's appearance and cultural differences contained in the expo haven't been widely recognized. Moreover, most of the former studies analyze cultural elements only based on culture and communication theories which are abstract. It is need to present cultural phenomenon by virtue of theories in other fields. The nature of communication can be seen as a sign exchanging process (Huang Yuhuang, 2006). Semiotics can help people to have a profound and complete understanding of cultural features.

This paper attempts to study the cultural features contained in the appearance of Chinese and American pavilions in Shanghai expo from the perspective of Pierce's semiotics so as to help people to have a clearer understanding of the two cultures and their differences.

\section{PIERCE'S SEMIOTIC THEORY}

American scholar Charles S. Peirce and Swiss linguist Ferdinand de Saussure are both regarded as the founder of modern semiotics. Peirce's semiotics which is different from Saussure's dyadic semiotics is a kind of triadic semiotics. He defines a sign as a triad made of three indecomposable elements: a representamen, an object, and an interpretant (Chandler, 2002, p.32):

A representamen: the form which the sign takes (not necessarily material);

An interpretant: not an interpreter but rather the sense made of the sign;

An object: to which the sign refers.

According to Peirce, "a sign... (in the form of a representamen) is something which stands to somebody for something in some respect or capacity. It addresses somebody, that is, creates in the mind of that person an equivalent sign, or perhaps a more developed sign. That sign which it creates I call the interpretant of the first sign. The sign stands for something, its object. It stands for that object, not in all respects, but in reference to a sort of idea, which I have sometimes called the ground of the representamen" (Peirce 1960, p.28). The interaction between the representamen, the object and the interpretant is referred to by Peirce as "semiosis". The relationship between the three elements can be 
seen in the following figure (Peirce 1998, P411):

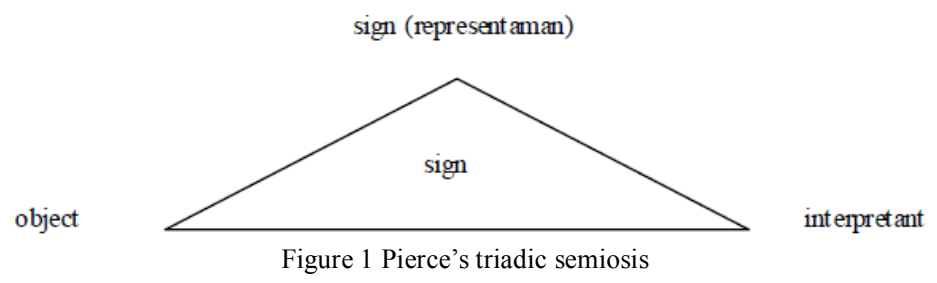

By "semiosis" I mean, on the contrary (to dyadic relation), an action, or influence, which is, or involves, a cooperation of three subjects such as a sign, its object, and its interpretant, this tri-relative influence not being in any way resolvable into actions between pairs. (Peirce, 1998, p.411)

Peirce's semiotic theory can be seen as a kind of cognitive philosophy. Thus, Peirce's semiotic theory is widely used to analyze signs with rich implications.

\section{The SEmiotic AnAlysis of the PAVILIONS’ ApPEARANCE}

Every element of the appearance in the pavilions of Shanghai expo is a sign adopted by the country to convey messages so as to communicate with people from other countries and show their own rich cultural deposit. As the first sight of pavilions, the appearance can be regarded as the most notable and typical representative of a country.

According to Peirce's semiotic theory, the appearance of pavilion is also made of three indivisible elements: the appearance of pavilion (the object), cultural connotations reflected by the object form (representative) and the cultural interpretation (interpretant). The relationship and interaction among these three elements can be shown by the following diagram:

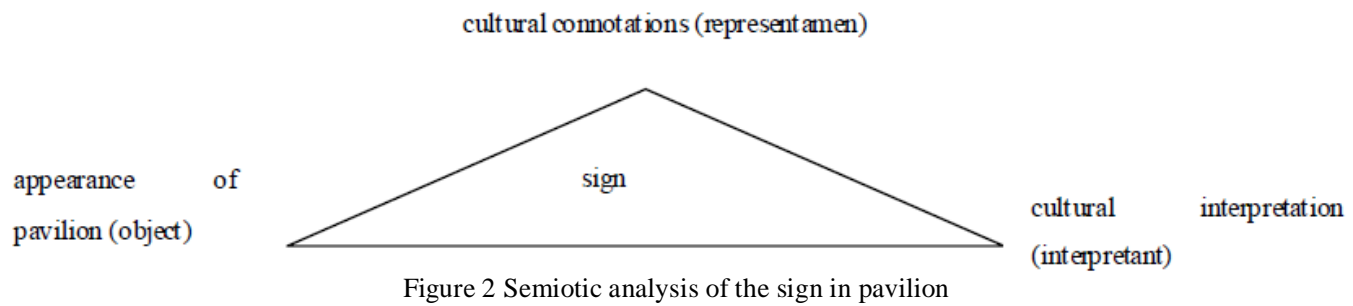

As a national feast, Shanghai expo expresses the philosophy of "understanding, communication, togetherness, and cooperation" to facilitate friendly international communication and improved cultural exchange. The process of semiosis is closely related to culture through the explanation of interpretant. A particular sign may have its unique meanings in certain culture. So elements of the pavilions' appearance must have rich cultural connotations which can be shown through the process of semiotic analysis and cultural interpretation.

\section{A. Semiotic Analysis of Chinese Pavilion's Appearance}

The most notable sign of Chinese pavilion is its appearance including the traditional dougong style, the 56 beams of it, the shape of the pavilion (which is like a Chinese original complex form of character “華”) and the color “Chinese red". This sign is a combination of icon and symbol.

The architectural style of Chinese pavilion is originated from the traditional Chinese dougong style which represents the culture of traditional Chinese architecture. It was widely used in the Spring and Autumn Period and developed into a complex set during the Tang and Song dynasty. Traditional Chinese architectures are mostly made of wood. Dougong, which is a system of interlocking wooden brackets inserted between the top of a column and a crossbeam, is a unique structural element in China.

In the dougong system, a large wooden block is placed on a column to provide a solid base for the bow-shaped brackets which support the beam or another one above it. Usually, the wood of squares is named dou, and the bow-shaped one is called gong. The main function of it is to provide a support for the weight of the horizontal beams that span the vertical columns by transferring the weight on it over a large area to the vertical columns (http://en.wikipedia.org). Another function of it is to heighten the eaves in order to get light well. The more the eave protrudes, the more layers of dougong are. Besides, this kind of design also has the decorative function and is traditionally used in crucial buildings such as palaces and temples. The number of the dougong layers is used to indicate the importance of building and the rigidness of hierarchy by the rulers. The end of each arch extends outward, so it possesses intricate artistic beauty through architectural treatment.

Among others, traditional Chinese buildings are most designed symmetrically. The main architecture of building is designed to lie on the central axis, and accessory ones are designed to surround it to achieve the symmetrical effect and give prominence to the main one. This kind of arrangement reflects Chinese traditional understanding to architecture 
and the pursuit to beauty. This type of inner beauty is harmony.

The traditional architectural style is successfully combined with modern techniques and factors in Chinese pavilion for the purpose of communication. So it may remind visitors of the importance of such style in traditional Chinese architecture and creativity and wisdom of our ancestors. On such a grand occasion, Chinese people display the traditional architecture rather than present one not only because of its special function and unique appearance, but also in accordance with the habit of introducing and taking example by traditional wisdom.

The main body of the building-dougong is supported by four large columns, and the dougong has 56 beams inserting each other for the purpose of supporting the building system. These beams can be seen as the symbols of Chinese 56 ethnic groups that support each other all the time for the prosperity and development of the country. China is a country with 56 ethnic groups which all have abundant distinct cultural deposits. Different from the "melting pot" USA, Chinese people are accustomed to emphasize the union of the nation in all sorts of occasions. This kind of character is the heritage from ancient times. In all ages, Chinese people are proud of contribution of different groups and usually stress unity on all sorts of occasions.

The 56 beams also represents that all the groups in China make their contribution to the world feast, and it can be explained that all the groups of people pool their efforts together to the country.

The appearance of the pavilion seems like a Chinese character “華” in the original complex form. The appearance of the pavilion is the representative of a country. This Chinese character reminds visitors of China's Chinese name. The original meaning of "hua" is flowery and illustrious. It also means Chinese nowadays because it is originated from the phrase "hua xia" which means glorious Chinese. Besides, it displays Chinese original complex character. This kind of character has rich cultural connotations. The stroke of Chinese character traditionally can be classified into eight basic forms. The order of writing Chinese characters is also essential. As we known that language is not natural and is created by people with the development of the society, and each language can reflect its own ethnic and cultural identity. Therefore, written language which is also created by certain people can reflect certain culture. Chinese people show an inclination of integrated thinking which means to consider the cognitive objects as a whole. There are many forms of integrated thinking including symmetry, doctrine, combination and linking (Zeng Li-ying, 2001). This kind of thinking pattern can be reflected by the structure of Chinese characters.

The theory that "man is the integral part of nature" is the core of traditional Chinese philosophy and governs their lives and behaviors in almost every aspect. This idea is a result of Chinese farming culture and stress the harmonious relationship between man and nature. It is a part of Chinese civilization and has influence on Chinese people's personality extensively. Meanwhile, the structure of Chinese characters can help us all remember the essence and importance of the thought of harmony.

Red is a typical color in China. It is frequently used by Chinese people to be the symbol of joy, happiness and hospitality. Most phrases connected with the word "red" have complimentary sense. It is said that the particular preference for red of Chinese are from the worship and expectation of sun (Ji Xiaojing, 2003). The blazing sun has a strong sense of mystery. Besides, the red color of sun represents beauty and holiness.

Traditionally, red is closely related to happy events such as wedding, joyous festival, birth, housewarming, advancement, to name but a few. On these occasions, people use red things to complement the lively and hotter atmosphere. Red character of "happiness", red candles, red bridal array, red lanterns and red flowers all symbolize pleasure, joy and happiness. Red also represents victory, success and fortune. If people pass entrance examination, their names will be presented on red papers. In happy events, such as spring festival, people also can get red envelops.

In old times, red also stands for riches and honor. Noblemen usually wore red clothes, and their homes would be painted with red lacquer. In traditional Chinese opera, people with red face are loyal, honest and upright. In modern times, it also can represent revolution. The revolution of communist party of China is called "red revolution". The word "red" is added also in the names of activities and in things related with communist party in China. For instance, "red songs" are songs to describe and praise the contribution of Chinese communist party. Red tour, red resources and red relics are also places and things related to the Chinese communist revolution.

In conclusion, red is a favorable color in China and has the connotation of lucky and happiness. The color of the pavilion not only displays traditional Chinese culture, but also reflects Chinese people's wishes to achieve a successful conclusion of Shanghai expo.

\section{B. Semiotic Analysis of American Pavilion's Appearance}

With the advantage of hosting world expo2010, China has more materials and funds. Comparatively, layout of American pavilion is simpler. Whatever it is plenty or casual, the appearance of the pavilions all can reflect and represent their unique culture.

The appearance of American pavilion is like an eagle spreading the wings. The roof garden looks like a hawk nest. As we known, eagle occupies a high position in American culture. American eagle which is also called the bald eagle is the national bird of the United States. The bald eagle has beautiful appearance and ferocious temperament. It is the representation of courage, strength and victory. The eagle motif is printed not only on the national emblem. It appears in their daily lives. It could be understood in a way that eagle is considered as the totem by Americans. Besides, the core of eagle culture is that the strong shall rule over the weak. In American, people believe that they must try their best to 
devote into their work and become powerful to be success. Thus, they use every opportunity to display their talents. Beside, eagle culture shows the philosophy that human nature is evil. Thus, they must strive to be good.

The eagle spreading wings makes visitors feel American people's hospitality and ambition. In front of the entrance of American pavilion, there is a grove of green trees and a new made artificially waterfall. This kind of design can prevent visitor from suffering insolation, and the water of the waterfall comes from water tanks. It also can remind visitors that American people can make full use of nature because they believe that human beings can master over nature by wisdom and creativity.

Meanings of signs are actually the products of human culture. The analysis of the two pavilions shows that the two countries have their own cultural features and there are differences between the two cultures. Thus, it is necessary to illustrate the deep roots of the cultural differences.

\section{Cross-Cultural Analysis of the Cultural Elements}

Value can be seen as the overall merit of people that guide them make choices and regulate behaviors. There are also values that tend to permeate a culture. Such values are called cultural values.

Cultural values are transmitted by a variety of sources (family, media, church, school, state, and so on) and therefore tend to be broad-based, enduring, and relatively stable. Most important, as is the case with cultural belief, cultural values guide both perception and communication. That is, our values get translated into action. An understanding of cultural values helps us appreciate the behavior of other people. An awareness of cultural values also helps us understand our own behavior (Samovar \& Porter; 2000: 60).

Kluckhohn and Strodtbeck are pioneers in the study of cultural value orientation. After examining hundreds of cultures, Kluckhohn and Strodtbeck(1961) concluded that people from different cultures has five different value orientations: human nature orientation, relationship of humankind to nature, time orientation, activity orientation and relational orientation. Besides, each orientation has three types. The types of them can be listed as follows: 1) Human nature: evil, mixture of good and evil, and good. 2) Human nature relationship- subjugation to nature, harmony with nature, and mastery over nature. 3) Time: past, present and future. 4) Activity: being, being-in-coming, and doing. 5) Relational: lineality, collaternity, and individualism. Thus, through the following analyses, the deep roots of cultural elements reflected by the pavilions are hoped to be deduced on the basis of Kluckhohn and Strodtbeck's value orientations.

\section{A. Cultural Analysis of Chinese Pavilion}

With five thousand years of civilization, Chinese culture has a long history. Influenced by Confucianism, the traditional Chinese belief about human nature is that man's nature at birth is good. In China, people believe that human's nature is basically good. People are pure and innocent when they come to the world. Such view can be presented in the structure of the stroke of Chinese character.

The value orientation of good human nature implicates that everyone is kind and can be kind to others. It guides people keep balance in life. So harmony plays an indispensable role in Chinese people's life. The importance of harmony in Chinese people's life can be shown in various aspects. Generally speaking, Chinese people value the harmonious relation with other people and nature. So they pay more attention to cooperate with others and get used to live harmoniously with every living creature in the world. In the design of Chinese pavilion, the interlocking structure of dougong style shows the cooperation between beams, and the 56 beams symbolizes the cooperation and power of all the ethnics in China. It obviously shows the spirit of collaternity in China.

Although the material of the pavilion is different from that in old times -the material of pavilion is not wood and there are lots of modern items, the use of this style can reflect the wisdom and creativity of traditional Chinese architecture. China is a country that values the effort of the ancients. It is traditional virtues that set an example for the ancients and learn from the past. This kind of character of Chinese people demonstrates the culture of this country is past-oriented which means believing strongly in the significance of prior events.

The traditional Chinese culture emphasizes that people should live harmoniously with nature and other people. Red color used in the appearance of the pavilion can be seen as the representative of hope and hospitality in China. From the perspective of cross-cultural communication, red which is widely used in grant occasions in China is also can be regarded as the symbol of cooperation. It encourages people to embrace together and make concerted effort for a better world.

\section{B. Cultural Analysis of American Pavilion}

American culture is characterized by individualism. Personal right and benefit is the supreme pursuit of American people. They believe that people can realize their values by their personal strivings and insistence. Respect and pursuit of individualism can motivate enthusiasm and bring most people's wisdom and potential into full play. Individualism is the core spirit of American value system. Pursuit of liberty and worship of development and competition are all features of American culture. Such characteristics are closely related with the history and religion of United States.

The concept of individualism in American has deep root. It can be traced back to the Puritanism which plays an important role for the establishment of the North American colonies. Strictly speaking, Puritanism can be seen as a kind 
of attitude or values more than religious group. Purists insist that everyone is equal and advocates thrifty, simplicity and self-dependence. Besides, American culture is influenced deeply by European colonists. Expansions of colony makes American people awake and realize the persecution from colonists. They fight for liberty, equality and democracy, and finally win. So this country extremely values people's right and self-dependence.

Generally speaking, eagle is the symbol of freedom, strength, power and victory. The bald eagle, the national bird of the United States, appears on many important objects, such as, seal of the president of the United States, national emblem and coins. American culture is closely related with eagle culture. Their attitudes towards human nature are that human beings are created evil, and they must strive to be good through self-independence.

Influenced by the history, geography and eagle culture, American people believe that human beings can live a better live by taking advantage of nature. In their mind, human beings powers are unlimited, and they can overcome all the nature forces with great effort. Thus, they can make full use of natural resources. The design of American pavilion reflects their belief vividly.

From the above analysis, it can be concluded that there are value divergences between the two countries which have different culture and history. The world is changing to be a small village because of increased communication. To live a better life, people from all over the world cooperate with each other. It is said that the cultures also face integration and globalization. Whereas, the deep values of a nation can not be shifted easily. Value differences can be presented on any occasion in any time.

\section{CONCLUSION}

There are signs around us, and everything conveying meanings can be seen as a sign from the perspective of semiotics. Most signs have their specific meanings, and they can explain different cultures and connotations more vividly. With the rapid development of world economy and policy, the communications between different cultures become increasingly frequent. It is important to make a comfortable communication. To avoid misunderstanding, it is necessary to understand different cultures.

Shanghai expo 2010, as a grand feast, can attract more attentions and express more cultural features. This paper analyzes the semiotic meanings and cultural connotations of appearance of the Chinese and American pavilions in Shanghai expo. It can be noticed that the two cultures all have their own unique features, although they all try to reflect the theme "one world, one dream". The signs, such as icons, symbols and colors, can be seen as the representatives of certain cultures. They all express certain meanings with their unique design and intensive verve. It's worth nothing that semiotic analysis of these visual elements can help people have a deep understanding. To sum up, it is not an easy process to learn various cultures. But we can understand different cultures from more pleasant way, which is appreciating their particular design of their pavilions.

\section{REFERENCES}

[1] Chandler, D. (2002). Semiotics: the Basics. London: Routlege.

[2] Guo-Ming Chen \& William J. Starosta. (2007). Foundation of Intercultural Communication. Shanghai: Shanghai Foreign Language Education Press.

[3] Gudykunst, W. (2007). Cross-cultural and Intercultural Communication. Shanghai: Shanghai Foreign Language Education Press.

[4] Peirce, C. S. (1960a). Collected papers of Charles Sanders Peirce. Volume II. Cambridge: Harvard University Press.

[5] Peirce, C. S. (1960b). Collected papers of Charles Sanders Peirce. Volume VIII. Cambridge: Harvard University Press.

[6] Peirce, C. S. (1960c). Collected papers of Charles Sanders Peirce. Volume V. Cambridge: Harvard University Press.

[7] Peirce, C. S (1998). The Essential Peirce: Selected Philosophical Writings, vol. 2(1893-1913) (The Peirce Edition Project, Ed.). Bloomington. IN: Indiana University Press.

[8] Samovar, L.A. Porter, R. E. \& Stefani, L. A. (2000). Communication Between Cultures (3rd.ed). Beijing: Foreign Language Teaching and Research Press.

[9] Samovar, L.A. \& Porter, R.E. (2007). Intercultural Communication: A Reader (10th ed.). Shanghai: Shanghai Foreign Language Education Press.

[10] Zeng Li-ying. (2001). Chinese Characters and the Way of Integrated Thinking. Journal of China Three Gorges University (Humanities \& Social Sciences), 3, 39-42.

[11] Zhuang Shu-juan. (2006). Comparison of the Color Symbolization between China and the Western Countries. Journal of Social Science of Jiamusi University, 5, 156-157.

[12] Huang Yuhua. (2006, 6). Understanding Intercultural Communication from the Perspective of Semiotics. http://auth.lut.cn/rewriter/LUT/http/c9f9v-me-mfc-s-9bnl9bm/Thesis_Y985324.aspx (accessed 11/3/2011).

[13] Ji Xiao-jing. (2003, 3). The Research of Semantic Connotations in Words Concerned with Colors. http://auth.lut.cn/rewriter/LUT/http/c9f9v-me-mfc-s-9bnl9bm/Thesis_Y555612.aspx (accessed 15/5/2011).

[14] http://en.expo2010.cn/ses/indexn.htm (accessed 10/11/2010).

[15] http://en.wikipedia.org/wiki/Dougong (accessed 12/5/2011). 
Shirong Zhang was born in Xining, China in 1972. She received her M.A. degree in linguistics from Northwest Normal University, Lanzhou, China.

She is currently an associate professor in the School of Foreign Languages, Lanzhou University of Technology, Lanzhou, China. Her major research interest is intercultural communication.

Fan Yang was born in Tianshui, China in 1987. She received her B.A. degree in foreign language and literature from Lanzhou University of Technology, Lanzhou, China in 2009.

She is now a postgraduate student in the School of Foreign Languages, Lanzhou University of Technology, Lanzhou, China. Her major research interest is intercultural communication. 